\title{
VARIEDADES LINGUÍSTICAS NA LOCALIZAÇÃO DE GAMES: DIALETOS E RAÇAS DO WORLD OF WARCRAFT
}

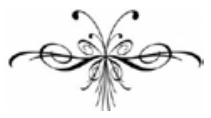 \\ Heber de Oliveira Costa e Silva
}

Resumo: O objetivo deste trabalho é entender mais sobre a natureza da localização de games investigando como a variação linguística é localizada em um game. Selecionamos a localização para o português brasileiro do jogo World of Warcraft (Blizzard Entertainment) para examinar a recepção, por parte dos jogadores, do produto localizado e das soluções adotadas pelos tradutores para lidar com o problema dos dialetos regionais e sociais usados para caracterizar as raças do jogo. Para tanto, coletamos e analisamos comentários de jogadores nos fóruns oficiais da Blizzard com relação ao uso desses dialetos regionais e sociais na versão localizada. Discutimos essa recepção pela ótica dos objetivos da localização (O’HAGAN \& MANGIRON, 2006; BERNAL-MERINO, 2008; DI MARCO, 2007), principalmente o de preservar a experiência de jogo para o público-alvo. Além disso, recorremos a estudos sobre variação linguística e tradução na literatura (como TAIVALKOSKI-SHILOV, 2003) para fazer um paralelo com nosso objeto, considerando a escassez de estudos sobre variação linguística na localização de games. Esperamos, como resultado, ter avançado um pouco mais na compreensão do processo de reconstrução da identidade das raças no game localizado, bem como ter lançado uma luz sobre os métodos usados pela localização de games para resolver questões de variação linguística.

Palavras-chave: Tradução. Localização de games. Variação linguística.

\begin{abstract}
The main objective of this paper is to understand more about the nature of game localization by investigating how linguistic variation is localized in a game. We selected the Brazilian Portuguese localization of the game World of Warcraft (Blizzard Entertainment) to examine the players' reception of the localized product and of the solutions adopted by the translators to deal with the issue of regional and social dialects used to characterize the races in the game. In order to do so, we collected and analyzed players' comments from official Blizzard forums on the usage of regional and social dialects in the localized version. We looked into this reception in the light of game localization's purposes (O'HAGAN \& MANGIRON, 2006; BERNAL-MERINO, 2008; DI MARCO, 2007), especially the goal of preserving gaming experience for the target audience. Considering that there are not enough works about linguistic variation in game localization, we resorted to studies on linguistic variation and translation in literature too (such as TAIVALKOSKI-SHILOV, 2003). As a result, we expect to have shed further light on the process of reconstructing race identity in a localized game as well as on the approaches by which game localization solves issues of linguistic variation.
\end{abstract}

Keywords: Translation. Game localization. Linguistic variation. 
$\mathrm{E}^{\mathrm{n}}$ mbora a atividade da localização já exista há algum tempo, estudos sobre o assunto são algo relativamente novo na indústria - e mais ainda na academia. A literatura fundamental desse campo é, portanto, recente. No caso de softwares em geral, a obra A practical guide to localization (2000), de Bert Esselink, é a referência pioneira. The game localization handbook (2005), de Heather Chandler \& Stephanie Deming, é um dos manuais técnicos mais citados em se tratando de localização de games ${ }^{1}$. No meio acadêmico, artigos e ensaios passaram a ser publicados há cerca de uma década, mas ainda há poucos livros, sendo Game localization (2013), de Minako O’Hagan e Carmen Mangiron, o mais importante até o momento.

Como se sabe, o termo localização tem origem na informática. O Houaiss (2001) já registra localizar como "adaptar (software) para o mercado local; traduzir (documentação de software)”, termo cuja etimologia remonta a locale. Esselink (2000, p. 1) $)^{2}$ explica que locale representa uma combinação específica de língua, região e codificação de caracteres ${ }^{3}$. Assim, para a Associação de Padrões da Indústria de Localização [Localization Industry Standards Association] (LISA), localização é tornar um produto linguística e culturalmente adequado ao locale (país/região e língua) onde será usado e vendido (ESSELINK, 2000, p. 3) ${ }^{4}$. Já Chandler \& Deming (2012, p. 4) definem a localização de games simplesmente como o processo de traduzir recursos linguísticos (p. ex., texto e dublagem) de um jogo para sua versão em outras línguas, atribuindo à internacionalização a tarefa de preparar outros recursos (p. ex., código e interface) para acomodar traduções para diferentes línguas $^{5}$. Bernal-Merino (2006, p. 31) considera localização um termo muito amplo para os Estudos da Tradução, afirmando que se poderia usar tradução para a definição de Esselink ${ }^{6}$. Assim, não admira que não haja ainda distinção clara entre os termos localização e tradução, que são usados de forma intercambiável até na indústria, como apontam O’Hagan \& Mangiron (2013, p. 104) ${ }^{7}$

\footnotetext{
${ }^{1}$ Adotaremos a terminologia localização de games para designar a atividade/área de estudo, visto que o termo game, já dicionarizado pelo Houaiss (desde 2001) como redução de videogame, designa jogo eletrônico. Em todo caso, qualquer uso da palavra jogo no âmbito deste trabalho deve ser entendido como jogo digital, videogame.

${ }^{2}$ São nossas todas as traduções para o português de textos publicados em língua estrangeira (cf. Bibliografia). Não usamos aspas em citações traduzidas por nós no corpo do texto, pois defendemos (COSTA E SILVA, 2011) que a tradução não é um discurso direto, mas uma reenunciação, similar ao discurso reportado.

3 “[...] a specific combination of language, region, and character encoding.”

4 "Localization involves taking a product and making it linguistically and culturally appropriate to the target locale (country/region and language) where it will be used and sold.”

5 "Localization is the actual process of translating the language assets in a game into other languages. For example, the text and voiceover assets [...] In comparison to internalization, localization is straightforward because it involves altering just the language assets and not other aspects of the game. [...] The main goals for internationalization of a game are designing a code base, core feature set, and UI that are generic enough to accommodate translations of any language."

6 “The term 'localisation' seems too broad a process involving several non-linguistic activities to be used in Translation Studies. In fact, Esselink's definition does not say anything that we could not apply to the term 'translation'.”

7 "[...] the division between translation and localization is not quite as clear-cut [...] often [used] interchangeably within the industry.”
} 
Motivada pela crescente onda de localização de games para o português nos últimos anos, a discussão chegou até os fóruns de leigos, onde se verifica essa mesma indefinição, mas também outras acepções — por exemplo: para alguns, localização (referindo-se à tradução em si) parece ser entendida como "adaptação", diferindo de tradução, que seria a "tradução literal”. Apesar de às vezes infundadas, não se deve desprezar completamente as discussões dos leigos, pois suas concepções vão influenciar sua recepção do game localizado e, portanto, sua experiência de jogo.

Enquanto entre os leigos a indefinição prevalece, na academia e na maior parte da indústria há uma nítida preocupação em distinguir os conceitos, tanto que Pym (2010) inclui a localização como um dos paradigmas dos Estudos da Tradução, ao passo que O’Hagan \& Mangiron (2004, p. 57) destacam:

A natureza da localização era diferente da tradução convencional no sentido de que a primeira requeria que o trabalho linguístico estivesse organicamente integrado ao processo de engenharia de software. Se por um lado a tradução ainda é o componente majoritário no processo de localização, por outro a localização requer que a tradução esteja incorporada ao próprio software, e processos e ferramentas especializadas para tanto. Ela também envolve ponderações maiores de marketing internacional. Por essas razões, o termo "tradução" talvez não parecesse representar o processo adequadamente. No princípio, a localização estava mais associada com a engenharia de software do que com a tradução, e a indústria de localização se desenvolveu de forma quase independente do setor de tradução já existente. ${ }^{8}$

Mesmo não sendo nosso objetivo aqui, vale ressaltar que, para ir mais a fundo na questão do porquê desses termos serem ou não empregados de forma intercambiável, seria preciso investigar, por exemplo, se o fato de a tradução ser vista como algo aparentemente rígido (fiel, inflexível, etc.) teria motivado a adoção da expressão localizar para nomear o próprio processo tradutório ou se, como questiona Pym (2010, p. 136), haveria vantagem comercial no emprego desses termos.

Este preâmbulo serve para ressaltar que, apesar dos múltiplos esforços, os estudos acadêmicos sobre localização de games (nos quais pretende se inserir este trabalho) ainda buscam definir seu objeto, seu escopo e suas especificidades. É por isso que, apoiados nos manuais técnicos, muitos dos primeiros trabalhos sobre o tema dedicam parte significativa de seus textos a apresentar a descrição do processo antes de analisarem o fenômeno da localização de games propriamente dita. Talvez seja por isso que O’Hagan \& Mangiron (2006, p. 11) afirmem que, embora a teoria ainda esteja tentando alcançar uma sintonia com a prática, o princípio comumente aceito na indústria é o de que o produto localizado deve manter a aparência e sensação ("look and feel”) do produto original ${ }^{9}$.

\footnotetext{
8 "The nature of the localization task was different from conventional translation in that the former required the linguistic work to be seamlessly integrated into the software engineering process. While translation still is the largest single component of the localization process, localization requires translation to be embedded within the software itself and calls for specialized processes and tools to support such tasks. It also involves wider considerations of international marketing. For these reasons, the term 'translation' perhaps did not seem to represent the process adequately. In its early days localization was associated with software engineering rather than with translation, and the localization industry was developed almost independent of the existing translation sector.”

9 "While theory is still catching up with the practice of localisation, a commonly accepted principle in the industry is that localised products should retain 'the look and feel of the locally-made products' (Fry, 2003).”
} 
Os manuais técnicos podem ser um importante ponto de partida para delimitar e contextualizar o campo de estudo, mas sua necessidade contínua de atualização (já que ferramentas e procedimentos são constantemente aperfeiçoados) faz com que seu potencial para o estudo da localização de games no âmbito acadêmico seja limitado. Uma razão para isso é que, além da parte técnica, entender a natureza da localização de games ${ }^{10}$ envolve refletir sobre sua relação com a tradução e a análise de casos concretos (como, p. ex., VIDAL \& ELIAS, 2012; MANGIRON, 2004).

Por essas razões, para além da reflexão teórica, optamos por investigar uma faceta da localização que ainda não foi bem explorada: a tradução de dialetos e variantes linguísticas na localização de games. Para tanto, escolhemos o caso da localização para o português brasileiro (PT-BR) do World of Warcraft (WoW), massive multiplayer online role-playing game (MMORPG) da produtora americana Blizzard Entertainment. Vale a ressalva de que a proposta aqui não é identificar ou desvendar as intenções dos tradutores ao adotarem esta ou aquela solução para traduzir o dialeto do game em inglês nem julgar o resultado final. Pretendemos analisar os efeitos gerados por suas escolhas - ou seja, o impacto da localização de dialetos e variantes sociolinguísticas do jogo na cultura-alvo, e como isso se reflete na percepção dos usuários - na crença de que isso possa ajudar a esclarecer um pouco mais a natureza da localização de games.

Em primeiro lugar, cabe explicar por que selecionamos especificamente esse jogo. Lançado em 2004, o WoW é um game de alcance mundial: tem hoje 7,6 de milhões de jogadores, mas já chegou a ter 15 milhões ${ }^{11}$. O’Hagan \& Mangiron (2013, p. 16) apontam o aumento de línguas-alvo para as quais o WoW foi localizado como indício da difusão dos games no mundo e, nesse contexto, citam o português brasileiro entre as línguas emergentes ${ }^{12}$. A versão em PT-BR do game (com três expansões) foi lançada em 2011, ainda que o WoW já tivesse uma base de fãs brasileiros que jogava em inglês. A localização incluiu todo o conteúdo produzido ao longo dos 7 anos do jogo, somando mais de 4 milhões de palavras e centenas de horas de áudio, e tendo levado cerca de 2 anos para ser finalizada (G1, 2011).

Talvez tenha sido positivo o fato de não ter sido um lançamento simultâneo (sim-ship) ${ }^{13}$, modelo que O’Hagan \& Mangiron (2006, p. 12-13) afirmam causar problemas aos tradutores, uma vez que no modo sim-ship eles não têm acesso ao jogo, tendo que traduzir linhas cujo contexto nem sempre está disponível ${ }^{14}$. Por outro lado, o fato de ser lançado posteriormente e ter uma base de usuários muito familiarizados com o game levou a comparações - e estas geraram discussões acirradas sobre as soluções da localização, e até mesmo sobre língua e tradução. Entre os usuários, os discursos foram diversos: alguns defenderam a localização pelo fato

\footnotetext{
${ }^{10}$ Partindo do conceito de locale dado por Esselink (supracitado), Mangiron \& O’Hagan (2013, p. 8) definem sucintamente game localization como o processo de adequar games a um determinado locale.

${ }^{11} \mathrm{O}$ WoW é o líder disparado no mercado de MMOs, com faturamento anual de 1 bilhão de dólares (FORBES, 2014).

12 Atualmente o valor do mercado brasileiro de games é de 1,5 bilhão de dólares e continua crescendo (SUPERDATA, 2014).

${ }^{13}$ Vamos analisar apenas a recepção do pacote lançado em 2011. Depois saíram mais expansões, desta vez em sim-ship.

14 "Localisers working under the sim-ship model are likely to face the added stress of having to carry out the task without being able to see - or play - the finished game and have to translate strings whose contexts are not always available."
} 
de não entenderem inglês; outros associaram o uso do jogo em português à valorização da língua nacional ou ao reconhecimento do trabalho de localização; outros alegaram ter havido descaracterização do jogo.

A tradução de nomes de personagens e lugares gerou uma polêmica à parte: alguns usuários argumentaram que isso quebrava uma suposta "regra de ouro da tradução": a de não traduzir nomes próprios, cuja origem e embasamento são desconhecidos. Ao contrário, O’Hagan \& Mangiron (2013, p. 176) dizem que, na localização de games, o mais comum é a substituição de um nome próprio por um que tenha referência análoga na cultura-alvo ${ }^{15}$, o que está de acordo com os objetivos da localização, que veremos adiante. Enfim, nesses debates ${ }^{16}$, surgiram conceitos, lugares-comuns e opiniões sobre o que é ou como deve ser a tradução/localização, o valor da língua nacional, etc. É da perspectiva dessa recepção (e não da produção) que abordaremos o tema da localização.

\section{Localização de games e variação linguística}

Para embasar a discussão posterior sobre a questão dos dialetos nos games localizados, é preciso primeiro discutir um pouco o que se concebe como objetivo da localização. O’Hagan \& Mangiron (2006, p. 14-15), abraçando o já citado princípio da "aparência e sensação", dizem que:

A principal prioridade da localização de games é preservar a experiência de jogo para o público-alvo, mantendo "a aparência e a sensação” do original. A incumbência do localizador é produzir uma versão que permitirá aos jogadores vivenciar o game como se tivesse sido originalmente desenvolvido na língua deles e proporcionar divertimento equivalente ao que foi sentido pelos jogadores da versão original. [...] Nos games, a fidelidade assume um sentido diferente na medida em que o tradutor não tem de ser fiel ao texto original, mas à experiência de jogo de modo geral. ${ }^{17}$

Di Marco (2007, p. 7) também partilha dessa visão: o objetivo da localização não é produzir uma equivalência literal em relação ao texto original, mas criar para o jogador-alvo o mesmo efeito na experiência de jogo que o texto original tentou criar. Bernal-Merino (2008, p. 32) acrescenta:

Videogames são desenvolvidos por uma equipe de pessoas criativas — não há um só autor - e sua nacionalidade não é necessariamente divulgada; na verdade, o jogo vai assumir qualquer forma que os desenvolvedores considerem apro-

\footnotetext{
15 "The strategy of substitution is often used, where the original name is replaced with a reference analogous in the target culture, with the aim of achieving a similar effect on the target user.”

${ }^{16}$ Como exemplo, vejam-se os tópicos "Bizarrices da tradução" (http://us.battle.net/wow/pt/forum/topic/3530213348) e "Tradução pt-BR” (http://us.battle.net/wow/pt/forum/topic/11353215240) do fórum oficial da Blizzard.

17 "The main priority of game localisation is to preserve the gameplay experience for the target players, keeping the 'look and feel' of the original. The brief of the localiser is to produce a version that will allow the players to experience the game as if it were originally developed in their own language and to provide enjoyment equivalent to that felt by the players of the original version. [...] With games, fidelity takes a different meaning whereby the translator does not have to be loyal to the original text, but rather to the overall game experience.”
} 
priada para a cultura de chegada a fim de garantir seu apelo e um alto grau de penetração no mercado. ${ }^{18}$

Se a “fidelidade” já é algo problemático e vago em tradução ${ }^{19}$, na localização, cujo foco principal é a cultura-alvo, o conceito torna-se mais vago, especialmente quando associado à experiência de jogo. De fato, O’Hagan \& Mangiron (2006, p. 15) dizem que a liberdade de incluir novos elementos, independentes do original, na localização de um game afasta-a da "fidelidade ao original”, que elas classificam como uma das noções centrais das teorias tradicionais de tradução ${ }^{20}$. Mas isso por si só não caracteriza a localização como algo novo, pois como aponta Pym (2010, p. 125), algumas dessas características já estariam previstas, por exemplo, na teoria do Skopos ${ }^{21}$. A isso, acrescentamos a afirmação de Di Marco (2007, p. 6):

\begin{abstract}
A localização cultural [...] é um processo que se situa entre a chamada tradução orientada para o leitor, "domesticadora", e a tradução orientada para a fonte, ou fiel. [...] [Envolve] a questão da objetividade, neutralidade e transparência da representação da versão original. Considerando as categorias do "verdadeiro" e do "autêntico", [a localização cultural] explora os limites do videogame como produto cultural e se distancia da representação fiel e da reprodução exata de culturas, buscando alcançar uma série de hibridizações. ${ }^{22}$
\end{abstract}

Na visão dessa autora, a localização está a serviço da cultura-alvo e, em termos de campo teórico, manteria pontos de contato com escolas cujo foco é o texto-alvo ${ }^{23}$. Não seria absurdo concluir, pelas afirmações acima, que a localização de games é assumidamente domesticadora ${ }^{24}$. De fato, O’Hagan \& Mangiron (2013, p. 236-241) classificam-na como um tipo de reescritura, dentro da teoria proposta por

\footnotetext{
18 "Video games are developed by a team of creative people, there is no single author, and they do not necessarily broadcast their nationality, in fact, the game will morph into whatever form publishers consider appropriate for the receiving culture to guarantee its appeal and a high level of market penetration."

${ }^{19}$ Argumentamos (COSTA E SILVA, 2011, pp. 53-65) que um dos problemas da fidelidade é partir do contexto de uma visão da língua como meio abstrato e mostramos que a fidelidade não se consolidou nem como teoria da tradução, tornando-se uma noção por demais imprecisa — e de modo geral impraticável.

20 “[...] the extent of freedom in including new features in game localisation, regardless of the original content, departs completely from one of the central notions of traditional translation theories: fidelity to the original.”

${ }^{21}$ Skopos (palavra grega adotada por escola europeia de língua alemã) é o propósito da tradução e está relacionado à função que a tradução desempenhará na situação de recepção. A Skopos Theorie é, então, um conjunto de proposições baseado na ideia de que o propósito de chegada (alvo) teria prioridade nas decisões do tradutor (Pym, 2010, p. 46).

22 "Cultural localization [...] is a process that stands between so-called reader-oriented or 'domesticating' translation and source-oriented or faithful translation. The cultural localization of video games involves the question of objectivity, neutrality and the transparency of the representation of the original version. Considering the categories of the 'true' and the 'authentic', it explores the limits of a video game as a cultural product and distances itself from a faithful representation and an accurate reproduction of cultures, attempting to achieve a series of hybridizations.”

${ }^{23}$ Para uma discussão sobre os paradigmas orientados para o alvo ou para a fonte, ver Pym (2010).

${ }^{24}$ Domesticação: estratégia de usar estilo fluente e transparente para minimizar a estranheza do texto estrangeiro (SHUTTLEWORTH \& COWIE, 2003, p. 43-44). Para aprofundamento, ver Venuti (1997; 2002).
} 
Lefevere $(2007)^{25}$, e usam o termo transcriação (ibid., p. 196-197), tomado a Haroldo de Campos, para descrever o que ocorre na localização de games.

Na localização de games, ocorre fato similar ao que Venuti (2002) e Lefevere (2007) apontam na literatura: games produzidos em línguas/culturas menos centrais são domesticados ao chegarem na cultura-alvo dominante. No entanto, na localização o contrário também ocorre: games produzidos na língua/cultura dominante (geralmente inglês/americana) são comumente domesticados quando chegam noutras línguas/culturas não centrais. Isso, aliás, é o mais frequente, até porque o inglês detém o status de língua franca na comunidade internacional de gamers (O’HAGAN \& MANGIRON, 2006, p. 13), o que faz com que até desenvolvedores cuja língua nativa não é o inglês o adotem na confecção de seus produtos. Essa bidirecionalidade da domesticação parece ter a ver com a própria especificidade da localização e com o fato de que, nessa indústria, o grau de penetração no mercado, de que fala Bernal-Merino (2008, p. 32), é fator mais relevante do que em outros setores da tradução profissional.

Cabe acrescentar que a localização de games difere da localização de softwares em geral por envolver aspectos como criação, narrativa, referências culturais, história, etc., além dos aspectos decorrentes da natureza interativa dos games, e da conexão emocional que se estabelece ao jogá-los, como apontam O’Hagan \& Mangiron (2013, p. 19), o que nos faz questionar se a localização de games estaria sujeita às críticas feitas à localização em geral por alguns teóricos (elencadas por Pym, 2010, p. 136-137). Esses aspectos permitem aproximar a localização de games da tradução literária e da tradução de outros produtos culturais. Talvez por essa razão Di Marco (2007, p. 2) afirme:

Partindo do princípio de que o texto de um videogame é constituído primordialmente não de linguagem, mas de cultura (sendo a representação verbal e não verbal, na verdade, um veículo do contexto social e moral a partir do qual um videogame é produzido), a localização cultural de videogames suscita questões relativas à traduzibilidade, compreensão e perda de significado, bem como à possibilidade de se estabelecerem novas identidades no espaço indeterminado da tradução cultural. $^{26}$

Nessa linha de raciocínio, O’Hagan \& Mangiron (2006, p. 15) dizem que os tradutores devem conhecer o registro, a terminologia, o humor, as alusões e referências à cultura pop, como filmes e quadrinhos, presentes no game. Di Marco (2007, p. 6) defende que é preferível evitar o uso de dialetos na localização de jogos, já que pertencem ao mundo real ${ }^{27}$. Mas cabe questionar: se um dialeto usado em um mundo fantástico remete ao mundo real, criando uma experiência para o jogador por lhe ser um elemento familiar, como proporcionar a mesma experiência ao

\footnotetext{
${ }^{25}$ A reescritura é uma categoria em que Lefereve (2007) inclui atividades como a tradução e a edição. Adepto do paradigma descritivo (ver Snell-Hornby, 2001, p. 22-25; Pym, 2010, p. 64-89; Hermans, 2004), ele partilhava da ideia de que toda tradução implica um grau de manipulação do textofonte para um propósito (HERMANS, 2004, p. 9).

26 "Assuming that the text of a video game thus consists primarily not of language but in fact of culture (verbal and non-verbal representation being, in effect, a vehicle of the social and moral background from which a video game is produced), the cultural localization of video games raises questions related to translatability, comprehension and loss of meaning, as well as to the possibility of establishing new identities in the indeterminate space of cultural translation.”

27 " [...] it is preferable to avoid the use of dialects in video game localization, since they belong to the 'real' world [...]."
} 
jogador da cultura-alvo sem fazer uso também de um dialeto real? Ou seja, como atingir o objetivo da localização?

Compreendemos a preocupação de Di Marco. Qualquer representação equivocada do outro ou da história pode suscitar desacordos. Em 2013, foi noticiada em sites especializados ${ }^{28}$ a polêmica gerada pelo game Company of Heroes 2, que foi rejeitado pelos russos por o considerarem uma distorção da história do país na Segunda Guerra Mundial. Esse exemplo comprova o que diz Bernal-Merino (2008, p. 31). Segundo ele, tudo - desde a representação do sangue até os eventos históricos - precisa ser reajustado para se enquadrar ao gosto e à tolerância de um país, de forma a não causar constrangimentos, e que essa é provavelmente uma das razões pelas quais muitos jogos se passam em mundos imaginários ${ }^{29}$. Ele afirma ainda (2008, p. 38) que:

[...] videogames, via de regra, não são feitos para darem a impressão de que pertencem a um país específico [...]. Pelo contrário, a maioria dos jogos produz mundos fictícios, onde os aspectos ideológicos, políticos ou religiosos do nosso mundo real têm pouca ou nenhuma influência, embora possam ser livremente baseados em culturas humanas reais. ${ }^{30}$

No caso do WoW, as inúmeras alusões à cultura ou à história geral em elementos internos e externos à narrativa são um caso à parte de intercruzamento desses mundos: o jogo se passa no mundo fictício de Azeroth, a narrativa é do tipo fantástica, típica do gênero RPG, mas as referências ao real são muitas ${ }^{31}$, criando um efeito de familiaridade e humor. Nesse mundo, habitam raças também fictícias, algumas caracterizadas por dialetos adaptados do mundo real, variantes sociais ou geográficas do inglês, bem como variações do inglês com sotaques estrangeiros.

Neste ponto, antes de avançarmos, é importante apresentar sucintamente algumas definições da sociolinguística ${ }^{32}$, começando pelo conceito de variação, que seria as "formas de dizer a mesma coisa no mesmo contexto", "resultado sistemático e regular de restrições impostas pelo próprio sistema linguístico em uso" (CAMACHO, 2007, p. 56, 58). Alguns outros conceitos que possibilitam entender melhor a noção de variação incluem (cf. HOUAISS, 2001; TRASK, 2008; CRYSTAL, 1999):

- Dialeto: 1. conjunto de marcas linguísticas de natureza semântico-lexical, morfossintática e fonético-morfológica, restrito a dada comunidade de fala inserida numa comunidade maior da mesma língua, que não chegam a impe-

\footnotetext{
${ }^{28}$ Entre eles, Relic or Russia: Who's Rewriting History in Company of Heroes 2? - GAME FRONT, 09/08/2013 (http://www.gamefront.com/company-of-heroes-2-russian/). Why gaming's latest take on war is so offensive to Russians - POLYGON, 25/07/2013 (http://www.polygon.com/2013/7/25/4553536/is-company-of-heroes-2-anti-russian).

29 “[...] depiction of blood or historical events, everything has to be readjusted to fit the country's tolerance and taste so as not to hurt sensibilities. This is probably one of the reasons why so many games take place in imaginary worlds.”

30 “[...] video games, as a rule, are not meant to be felt as belonging to a particular country [...]. On the contrary, most games develop fictional worlds, where our real ideological, political or religious world has little or no bearing at all, although they might be loosely based on real human cultures."

${ }^{31}$ Vale destacar que o WoW não passou por um completo processo de internacionalização tal como descreve Pym (2010, p. 123), ou seja, não foi diluído em uma versão intermediária, “world-ready”. Pelo contrário, mantém muitas especificidades da cultura americana, como as já citadas referências à cultura pop.

${ }^{32}$ Para uma visão geral do campo, ver Alkmin (2007) e Camacho (2007).
} 
dir a intercomunicação da comunidade maior com a menor. (Pode ser geográfico ou social.). 2. qualquer variedade linguística coexistente com outra e que não pode ser considerada uma língua (p.ex.: no português do Brasil, o dialeto caipira, o nordestino, o gaúcho etc.).

- Socioleto (dialeto social): cada uma das variedades de uma língua usadas pelos grupos de indivíduos que, tendo características sociais em comum (p.ex., a profissão, os passatempos, a geração etc.), usam termos técnicos, ou gírias, ou fraseados que os distinguem dos demais falantes na sua comunidade.

- Variedade/variante: cada uma das modalidades em que uma língua se diversifica, em virtude das possibilidades de variação dos elementos do seu sistema (vocabulário, pronúncia, sintaxe) ligadas a fatores sociais e/ou culturais (escolaridade, profissão, sexo, idade, etc.) e geográficos. São variedades sociais e/ou culturais: a língua padrão, a língua popular, a linguagem dos pescadores etc.; são variedades geográficas: o português do Brasil, o português de Portugal, falares regionais carioca, nordestino etc.

- Idioleto (dialeto individual): variante linguística de um único indivíduo num determinado período de sua vida, que reflete suas características pessoais, os estímulos a que foi submetido, biografia, etc.

- Sotaque: pronúncia característica de um país, de uma região, de um indivíduo etc. Usado popularmente como sinônimo de dialeto, mas em linguística considera-se como característica somente da oralidade.

Por sua abrangência, adotaremos o termo dialeto para nos referirmos às variedades linguísticas em geral, especificando-as quando for necessário (regional, social, individual), mas recorrendo a outros conceitos ocasionalmente.

Voltando ao tema geral deste texto, é relevante destacar que há poucos estudos sobre variação linguística em games localizados - uns poucos artigos e trechos curtos no já citado Game Localization. Então, baseados na aproximação entre a localização de games e a literatura estabelecida acima, recorremos a estudos de tradução literária para estabelecer um paralelo.

Como se sabe, os dialetos aparecem em muitas obras literárias. Taivalkoski-Shilov (2003, p. 48) aponta que o emprego de um dialeto, tal como o dos negros americanos em $O$ Som e a Fúria, de W. Faulkner, pode ser um gesto significativo do autor para marcar a problemática racial ou social de sua obra e que os dialetos distanciam ou aproximam os leitores dos personagens e do contexto cultural ${ }^{33}$. Isso mostra que a tradução de dialetos é questão extremamente importante em uma obra traduzida. Federici (2011, p. 1) aponta que a busca pela solução de problemas na tradução de variedades não padrão deve ser visto como um desafio construtivo, produtivo e criativo ${ }^{34}$. O fato é que, independentemente do caminho adotado, o tradutor não tem como fugir ao problema do dialeto.

\footnotetext{
${ }^{33}$ Como veremos, o mesmo se deu no caso do WoW, com jogadores se identificando ou rejeitando dialetos.

34 “The search for solving problems of rendering non-standard varieties has to be perceived as a constructive, productive, and creative challenge.”
} 
Para Folkart (1991, p. 232), é virtualmente impossível transpor para uma outra língua um segmento dialetal ou socioletal de modo a garantir que esse tenha a mesma inserção na economia sociolinguística do sistema de chegada ${ }^{35}$.

Comentando sobre a tradução literária, Taivalkoski-Shilov (2010, p. 3) afirma:

[...] estudiosos da tradução observaram mudanças que diminuem o polilinguismo (isto é, a diversidade de línguas, socioletos, registros, etc.) do texto-alvo. A redução do polilinguismo pode indicar duas coisas: primeiro, pode simplesmente significar a uniformização da língua e dos registros do texto-alvo [...]. Esse tipo de mudança é, na verdade, muito comum na literatura traduzida e reflete o fato de que o tradutor deixou de fora várias características do ato de fala original quando o reportou. As razões podem ser culturais (normas da cultura-alvo), linguísticas (inexistência de registro similar na língua-alvo), idiossincráticas (gosto pessoal do tradutor e objetivos da tradução) ou (por que não?) pura coincidência. $^{36}$

Que soluções adotar, então? Em sua tese, a mesma autora (2003, p. 48-51) elenca duas formas de lidar com a variação linguística na tradução literária: (1) o método gladkopis (em russo, "escrita suave”), que seria a neutralização dos socioletos por destituição total ou parcial dos fragmentos de linguagem não convencional do texto de partida ${ }^{37}$; (2) o método dialeto por dialeto, que consiste na substituição direta do dialeto do texto de partida por um dialeto "endógeno", apoiando sua representação socioletal (que consiste em efeitos de real) em um falar claramente identificável da cultura de chegada ${ }^{38}$. A autora aponta aspectos negativos nos dois: o primeiro basicamente elimina a variação e, com ela, às vezes as características dos personagens e até o tema da obra; e o segundo pode criar dificuldades de verossimilhança e afastar o leitor do mundo ficcional.

Note-se que o ponto de vista dos autores citados parte sempre do textofonte: algo da cultura-fonte está deixando de ser vertido para o texto-alvo - e, para eles, isso é um problema. A tese de Berman (2005), em especial, é de tratar a tradução como “experiência do estrangeiro”, cujo objetivo é proporcionar o contato com aquilo que é de fora, que nos é estranho. Percebe-se que, apesar de a situação a ser enfrentada pelo tradutor ser a mesma (a presença de dialetos), essa visão da tradução literária afasta-se da visão dos teóricos da localização de games. E a razão da divergência está no propósito, pois, como vimos, a localização assumidamente quer assimilar qualquer sinal de estranhamento e torná-lo familiar.

\footnotetext{
35 “[Il] est virtuellement impossible de remediatiser dans une autre langue um segment dialectal ou sociolectal de façon à lui assurer la même insertion dans l'économie sociolinguistique du système d'arrivée [...]."

36 “[...] translation scholars have noted shifts that diminish the polylingualism (i.e., the diversity of languages, sociolects, registers etc.) of the target text. The reduction of polylingualism in translation can mean two things. First it can simply mean the uniformization of the language and of the registers of the target text [...]. These kinds of shifts are in fact very common in translated literature and reflect the fact that the translator has left out various features of the original speech act from his/her report. The reasons may be cultural (the norms of the target culture), linguistic (non-existence of a similar register in the target language), idiosyncratic (the translator's taste and goals of the translation) or (why not?) coincidental."

37 “[...] la neutralisation des sociolectes du texte de départ par l'éviction totale ou partielle des fragments de langage non conventionel du texte de départ."

38 “[...] le traducteur substitue un sociolecte 'endogène' directement au sociolecte du texte de départ. [...] [Il] appuye sa répresentation sociolectale (qui consiste en effets de réel) sur un parler nettement local de la culture d’arrivée.”
} 
Na localização de games, O’Hagan \& Mangiron (2013, p. 177) dizem que a variação linguística presente no texto-fonte muitas vezes causa problemas quando se traduz jogos do inglês ${ }^{39}$. Prosseguem dizendo que, dadas as implicações e o risco de afastar o público-alvo, o acréscimo de sotaques acarreta uma sérias decisões tradutórias, que são às vezes tomadas pelo produtor do jogo em vez do tradutor. Segundo elas, ocorre na localização de games a neutralização do sotaque no caso, por exemplo, de não haver sotaques locais que reflitam as conotações do original; mas destacam também (2013, p. 165) uma estratégia que consideram característica da localização de games: a inserção de um dialeto no texto-alvo quando não havia no texto-fonte ${ }^{40}$.

$\mathrm{O}$ caso do WoW interessa porque, à semelhança do que ocorre nos romances, os vários falares e dialetos ajudam a compor o universo do jogo — criam identidades, caracterizam raças e também estabelecem um ponto de contato cultural com o jogador pelo reconhecimento desse dialeto. As referências culturais, que já citamos, acabam tendo o mesmo papel de oferecer ao jogador algo que ele conhece. Então, podemos dizer que, em jogos como o WoW, elementos do real como dialetos e referências (ou seja, a cultura local) são o componente familiar, enquanto o mundo fantástico do jogo proporciona uma experiência de estranhamento. Em outras palavras, a cultura local funciona como contraponto da ficção, oferecendo ao jogador uma ponte com o real, com sua própria identidade e cultura, criando assim um vínculo de familiaridade com ele ${ }^{41}$.

Assim, podemos concluir que, na versão localizada do jogo, o universo fantástico continuará provendo a experiência do estrangeiro; enquanto o vínculo familiar será necessariamente proporcionado pela cultura-alvo (através da inserção de elementos seus do real), já que a cultura estrangeira, onde foi produzido o jogo original, serve de vínculo àquele outro jogador, o que joga o jogo na língua-fonte, mas não serve para o novo jogador, o da cultura-alvo.

Portanto, do ponto de vista teórico, na localização de games, o etnocentrismo e a domesticação são o caminho legitimado para lidar com o que é de outra cultura e, assim, atingir seu objetivo: fazer com que variantes linguísticas e referências culturais alcancem a mesma função que tinham no jogo original. Faz sentido, então, que o método adotado na localização do WoW para o português do Brasil tenha sido a substituição das variantes linguísticas por dialetos da cultura-alvo.

Passemos agora a analisar a recepção dos jogadores brasileiros a essa estratégia de substituição de dialetos. Para isso, examinamos elementos de localização das raças mais comentadas nos fóruns de usuários, que acabaram sendo aquelas cujos falares são mais marcados pela variação linguística, a saber: trolls, anões, draeneis e goblins ${ }^{42}$ — fato que supomos não ter sido mera coincidência, considerando

\footnotetext{
39 "Linguistic variation present in the ST often cause problems when translating games from English $[\ldots] . "$

40 "One important strategy for dealing with linguistic variation in the form of dialect in game translation involves the introduction of a dialect in the TT where there is none in the ST."

${ }^{41}$ É claro que, quando o dialeto real está associado a uma representação do mundo real no game (se este, por exemplo, é histórico ou se passa num país ou numa época real), a transposição de dialetos entre línguas/culturas, embora ainda faça a "ponte com o real”, pode gerar ruído ou distanciamento em vez de familiaridade, obrigando a outras soluções.

${ }^{42}$ Atualmente, o WoW tem 13 raças jogáveis: anão, draenei, elfo noturno, gnomo, humano, worgen (membros da faç̧ão Aliança); elfo sangrento, goblin, morto-vivo, orc, tauren, troll (membros da Horda); e pandaren (neutro).
} 
o que vimos até aqui sobre o impacto e os efeitos de se utilizar representações de dialetos em produtos culturais como a literatura e os games.

Não encontramos declarações oficiais da Blizzard sobre a caracterização das raças no WoW, mas na WoWWiki $i^{43}$ e em diversas postagens do fórum oficial Battle.net em inglês, usuários reconhecem os dialetos dos trolls, anões e goblins como sendo similares ao do Haiti/Jamaica, Escócia (Highlands) e Brooklyn/New Jersey, respectivamente, enquanto os draeneis falam inglês como alguém do Leste Europeu ou do Oriente Médio.

\section{Recepção da localização do WoW para o português brasileiro}

Em primeiro lugar, cabe ressaltar que, assim como os dialetos do jogo original não são reproduções exatas dos dialetos do mundo real (apenas utilizam-nos como base), a localização para o português brasileiro também usou os dialetos do Brasil somente como base. Como também não há nada divulgado oficialmente sobre essas escolhas dialetais do processo de localização, investigamos aqui como os próprios jogadores brasileiros reconheceram e nomearam os dialetos da versão localizada e que efeitos isso teve sobre sua experiência de jogo.

É preciso ressaltar também um aspecto linguístico básico do universo ficcional do jogo: houve comentários nos fóruns brasileiros que tratavam o inglês como a língua original do WoW, mas não é esse o caso: o inglês é uma representação da "língua comum” (Common) ${ }^{44}$. Essa língua comum fazia o papel de koiné, ou seja, língua franca, no universo Warcraft. A princípio, todas as raças conseguiriam se comunicar na língua comum, mas, especificamente no WoW, devido à agressividade entre jogadores das facções ${ }^{45}$, a Blizzard decidiu criar um recurso que codifica as mensagens e impede os adversários de se comunicarem ${ }^{46}$, justificando-o com a ideia de que a Horda falaria órquico ${ }^{47}$ e a Aliança falaria a língua comum. O inglês passa então a representar também o órquico (para os jogadores da Horda). Esse caráter "curinga" esvazia qualquer argumento de o jogo estar indissociavelmente arraigado à língua inglesa: o lugar ocupado pelo inglês pode ser ocupado por qualquer outra língua, pois sua função é meramente representativa. Isso é apropriado à localização, cuja intenção é, como vimos, emular um “novo original” em uma nova cultura.

Ainda que com certo anacronismo medieval típico dos mundos do RPG, o inglês padrão é usado para a maioria das raças no jogo. Esse inglês assume, então, função de parâmetro linguístico: algumas raças falam “diferente”, ou seja, têm suas

\footnotetext{
43 Conhecidas fontes de referência extraoficiais sobre o universo Warcraft são WoWpedia e WoWWiki. Esses sites são boas fontes para conhecer o ponto de vista da recepção dos usuários sobre o jogo.

${ }^{44}$ Segundo a WoWpedia, a língua comum é tradição em jogos de RPG, consolidada principalmente pelo famoso Dungeons \& Dragons, derivada da ideia do Westron, a língua franca do universo criado por J. R. R. Tolkien.

${ }_{45}$ Ainda de acordo com a entrada Common (language) da WoWpedia.

${ }^{46}$ Jogadores alegam que a solução não tem explicação no lore (conjunto de histórias do jogo), especialmente com a criação dos pandarens (raça neutra), que não podem mais se comunicar entre si depois que optam por uma facção. A julgar por toda essa discussão, percebe-se que a questão das línguas é central na experiência dos jogadores.

${ }^{47}$ A língua dos orcs, raça muito conhecida no universo fantástico e usada desde início da série de jogos Warcraft.
} 
falas reconhecidas como variantes linguísticas, sendo as mais evidentes justamente as raças mencionadas nos comentários que discutem a questão dos dialetos. Passemos a analisar amostras desses comentários a fim de verificar qual foi a recepção dos jogadores e de que forma se deu a construção de identidade das raças por meio dos dialetos.

\section{Amostra 1 - Battle.net/wow}

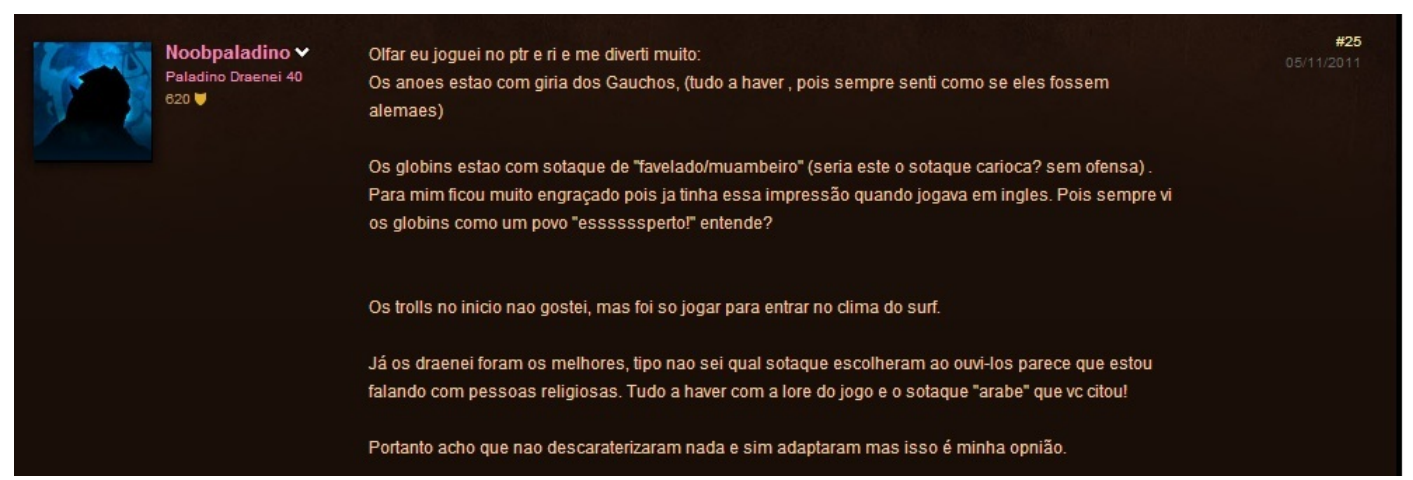

Escolhemos essa como a primeira amostra a analisar porque aborda de uma só vez todas as raças aqui comentadas. Além disso, usa categorias que veremos também em outros comentários - como "sotaque" e "gíria" - para nomear as características fonéticas e lexicais das variedades linguísticas. Esse usuário identifica os anões como gaúchos pelo léxico ("gíria”), relacionando os anões com a colonização alemã do Sul. É frequente também a associação social-regional (como a que ele faz com goblins, acima): por exemplo, muitos usuários associam o dialeto carioca a papéis sociais estigmatizados como favelado, traficante, muambeiro, malandro, esperto, surfista, justificando o rótulo através da variedade linguística e procurando ao mesmo tempo características das raças que corroborem sua visão. O jogador da Amostra 1 ainda faz uma associação entre “árabe” e "religioso" quando fala dos draeneis ${ }^{48}$, que se repete também na amostra seguinte:

Amostra 2 - Battle.net/wow

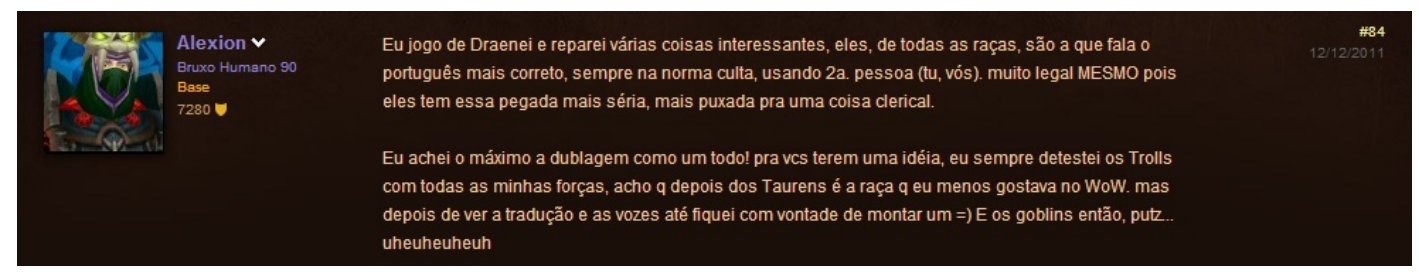

Novamente, a visão que o jogador tem da raça é construída pelo dialeto social. Ele menciona ainda o uso da norma culta ("correto") associando-a com seriedade e religiosidade (“clerical”). Neste ponto, cabe dizer que, na localização brasileira, a língua comum é representada pelo que se pode chamar de português culto ${ }^{49}$,

\footnotetext{
${ }^{48} \mathrm{Na}$ versão pt-BR, os draeneis falam na $2^{\circ}$ pessoa (singular e plural), o que muitos identificaram como exótico.

${ }^{49}$ Ilari (TRASK, 2008, p. 326-327) fala do extenso Projeto de Estudo da Norma Urbana Culta (Nurc), cujos resultados não permitem identificar o português culto com o descrito nas gramáticas
} 
variedade em que algumas formas verbais indicadas pela gramática prescritiva (p. ex., a $2^{a}$ pessoa do plural) são raras ou não existem. Assim, o uso da "norma” tradicional, que alguns identificaram como a variante de Portugal, reforça o estranhamento em relação aos draeneis e até acrescenta algumas características à raça. Torna-se visível aí a experiência do estrangeiro, que na localização é o contato com o estranho universo do jogo.

Passemos a algumas amostras sobre os trolls, uma das raças que geraram mais polêmicas. Tal como o jogador da Amostra 1, outros associaram os trolls a dialetos regionais/sociais:

Amostra 3 - Battle.net/wow

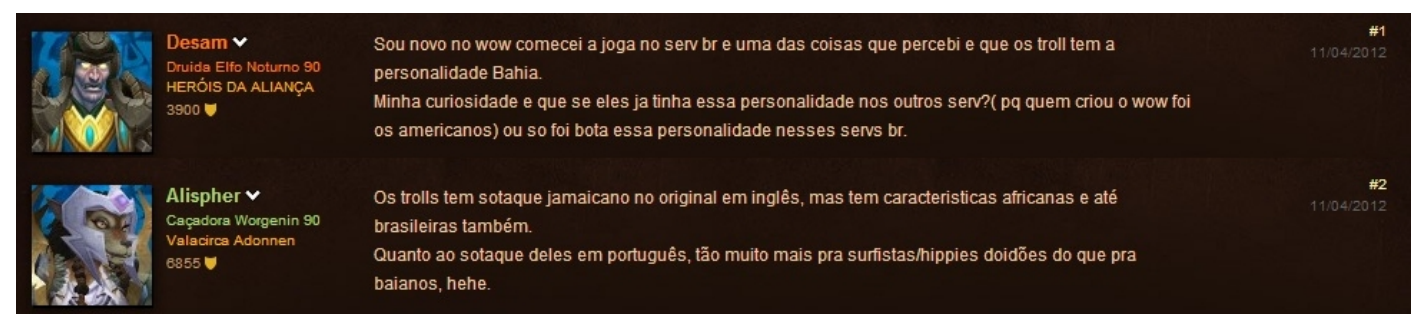

Neste caso, quando um usuário do fórum fala sobre "personalidade”, outro inclui o "sotaque" na resposta, mostrando que, no imaginário desses jogadores, o dialeto é visto como algo que identifica um grupo ou indivíduo, que faz parte da personalidade dele(s). Em outra ocasião, os usuários do fórum continuam debatendo a identidade regional e social dos trolls, agora "brasileiros”, em termos dos falares, de seus hábitos e condições sociais:

Amostra 4 - Battle.net/wow

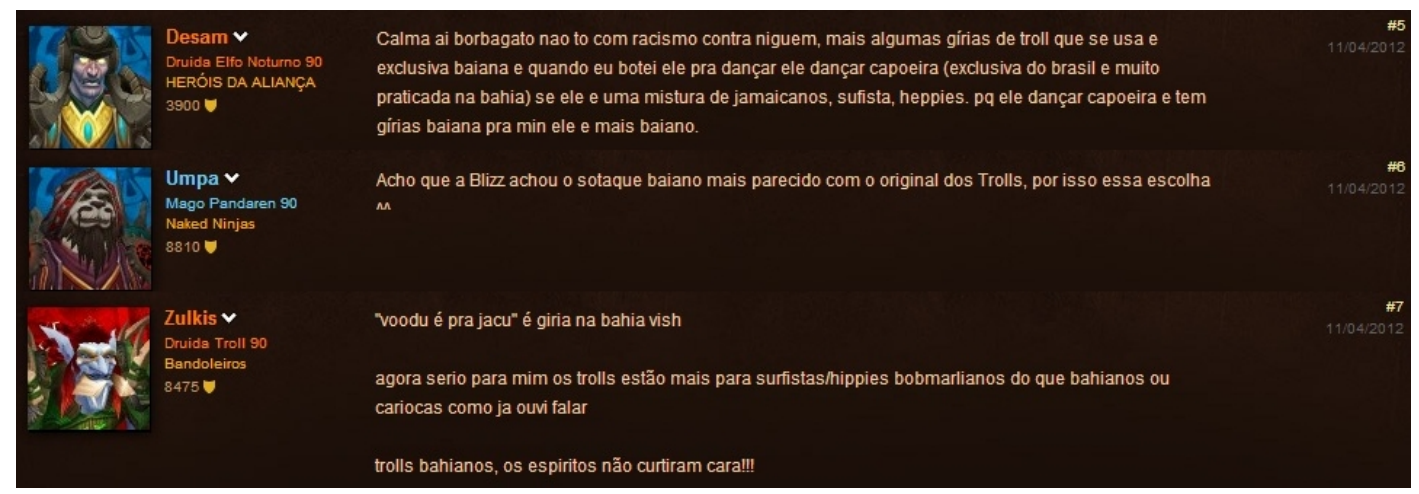

Amostra 5 - Battle.net/wow

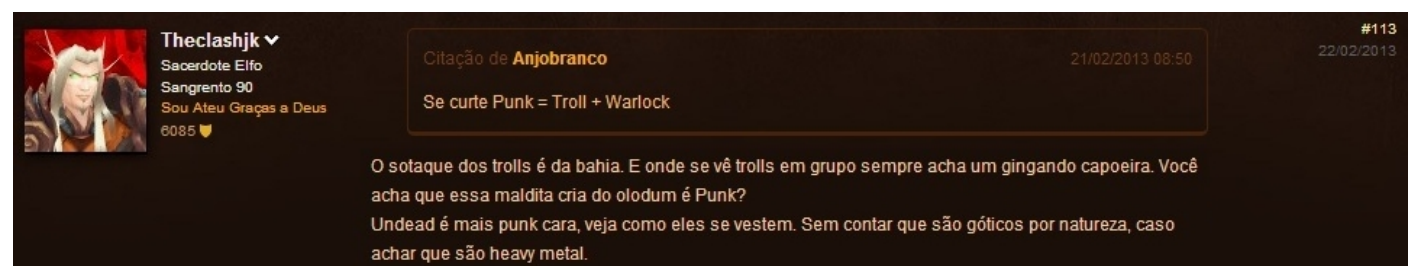

tradicionais (padrão). Segundo ele, a maior parte dos falantes cultos do Brasil usa o paradigma verbal eu vou, ele/você/a gente vai, nós vamos, vocês/eles vão. 
Amostra 6 - Battle.net/wow

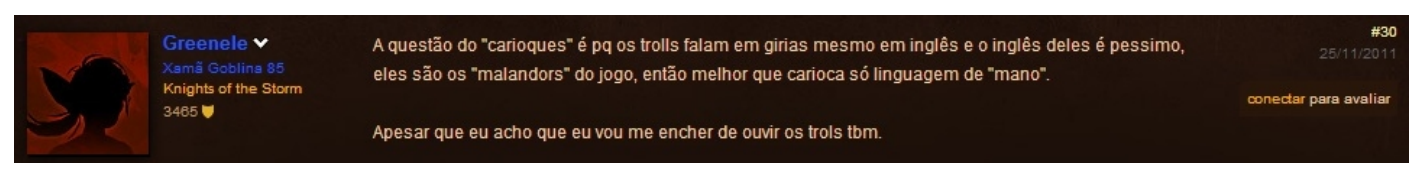

Amostra 7 - Battle.net/wow

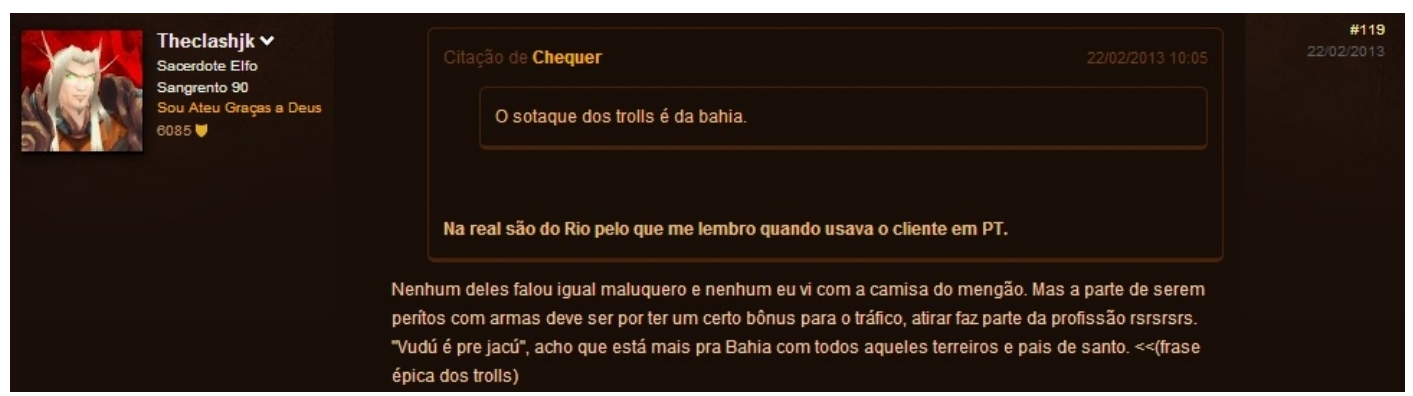

Note-se que, na Amostra 5, surgem os estereótipos sobre baianos (capoeira, olodum) e, nas Amostras 6 e 7, emergem estereótipos e preconceitos sobre o carioca e seu falar (são malandros/maloqueiros, falam errado e com gírias, usam armas, torcem para o Flamengo). Um jogador também compara o "carioquês" em tom pejorativo ao dialeto paulistano ("mano"). Embora os "malandros do jogo", no sentido de usar esperteza para enganar, sejam os goblins ${ }^{50}$, essas concepções preconceituosas, deduzidas meramente a partir do dialeto carioca, passam a caracterizar os trolls. Como alguns consideraram trechos da dublagem do WoW como "carioca", essa visão estereotipada também contaminou a recepção de outras raças, como vemos nesta amostra:

Amostra 8 - Battle.net/wow

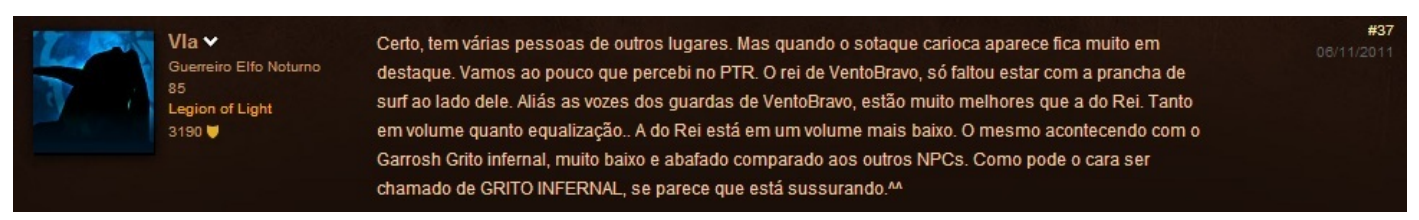

O que parece incomodar o jogador não é o fato em si de o rei falar (na opinião dele) a variante carioca, mas a não adequação do estereótipo (surfista, deduzido a partir do dialeto carioca) à visão que ele tem de como deve falar/se comportar um rei. Em última instância, podemos perceber que a maioria das críticas e elogios à localização ${ }^{51}$ têm relação com a adequação ou não do(s) dialeto(s) ou tipo(s) humano(s) identificado(s) com dialeto(s) à visão pessoal do jogador sobre a identidade das raças. Essa identidade, inclusive, pode ser a identidade social e regional dos próprios jogadores. Vejamos mais alguns comentários, em especial sobre os anões:

\footnotetext{
${ }^{50}$ Ver Goblin (http://us.battle.net/wow/pt/game/race/goblin), na seção Raças do World of Warcraft do Battle.net.

${ }^{51}$ Ver mais comentários, coletados em outros sites e fóruns, no Apêndice deste trabalho.
} 
Amostra 9 - Battle.net/wow

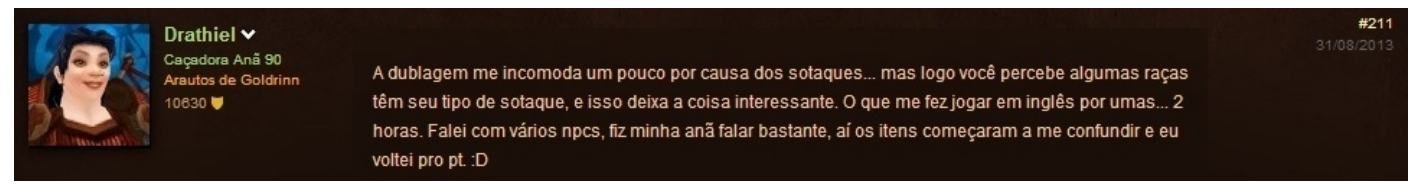

Amostra 10 - Battle.net/wow

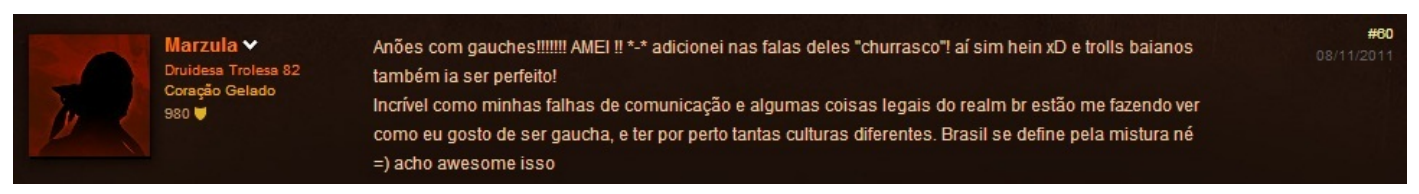

Amostra 11 - Battle.net/wow

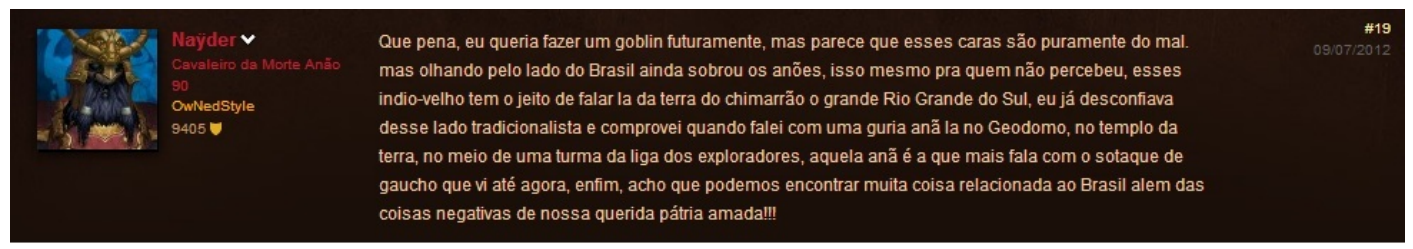

Amostra 12 - Battle.net/wow

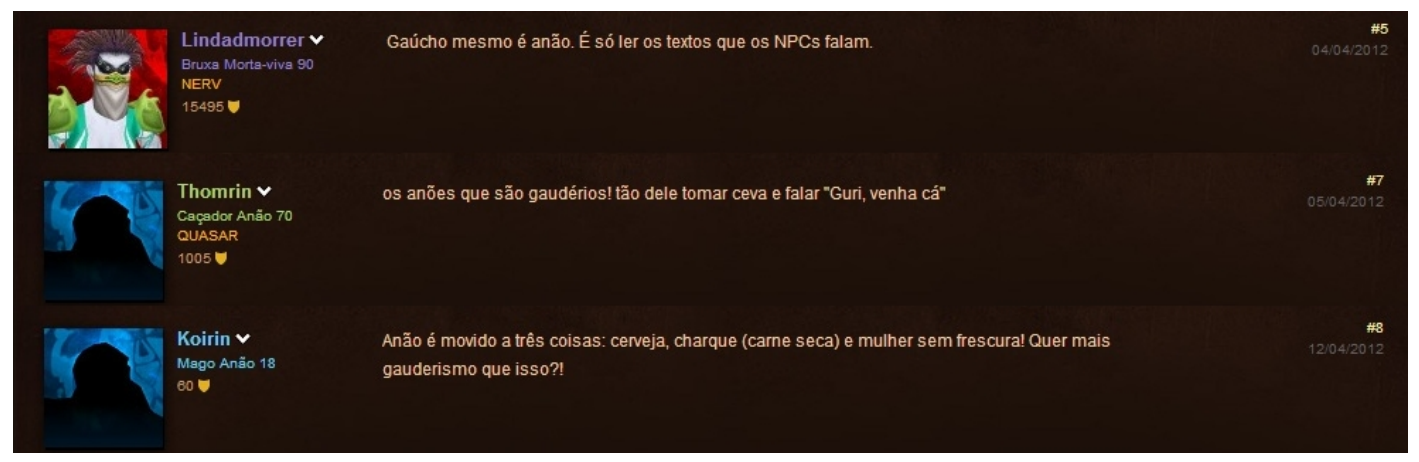

Esta série de comentários (Amostras 9 a 12) mostra como a representação dos anões gerou uma identificação que não constatamos na localização de outras raças. Existe também o contrário: na Amostra 11, o usuário deixa subentendido que buscava nas raças essa identificação com o Brasil, mas, apesar de os goblins se encaixarem nesse requisito, a imagem negativa deles afastou o jogador dessa esco$\mathrm{lha}^{52}$ - por outro lado, ele claramente se identifica com os anões, inclusive usa o dialeto para expressar isso. A discussão sobre os anões também abordou aspectos linguísticos, com usuários criticando ou defendendo o dialeto gaúcho com base em suas visões de língua.

\footnotetext{
${ }^{52} \mathrm{O}$ tópico de onde foi tirada a Amostra 11 era "Goblins são Brasileiros”. O autor, a título de humor, listou aspectos como "fila de banco", "trabalho mal remunerado", "estradas feitas nas coxas", "jeitinho goblínico", gerando uma longa discussão que acabou entrando também em aspectos da língua (http://us.battle.net/wow/pt/forum/topic/6037345795).
} 
Amostra 13 - Battle.net/wow

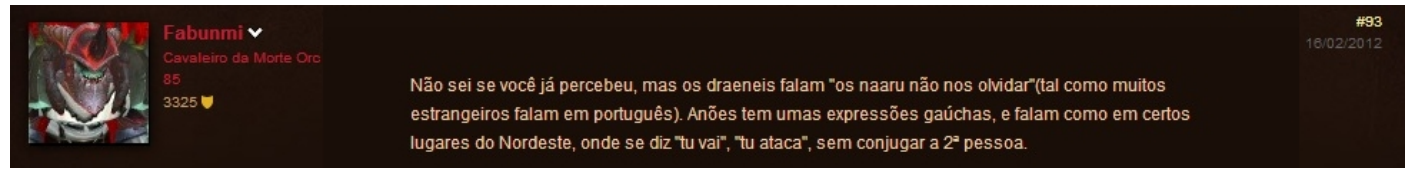

O jogador da Amostra 13 expressa o estranhamento para com os draeneis que já vimos acima e diz que a não conjugação da $2^{a}$ pessoa seria típica de “certos lugares do Nordeste”. Outros usuários identificam esse paradigma verbal, que estudos apontam como português do Brasil ${ }^{53}$ :

Amostra 14 - Battle.net/hearthstone

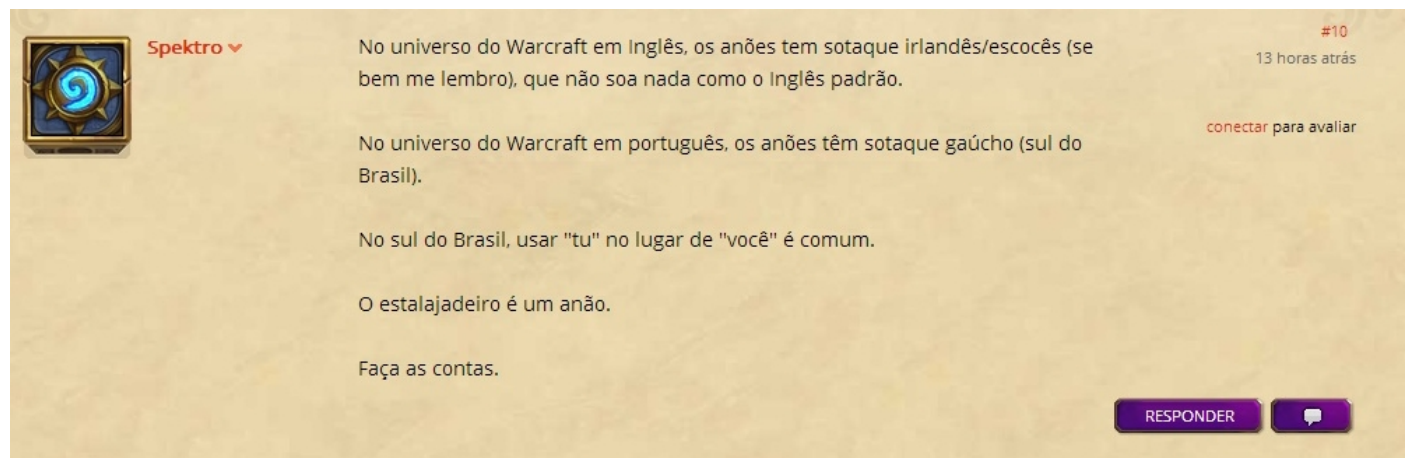

Amostra 15 - Battle.net/hearthstone

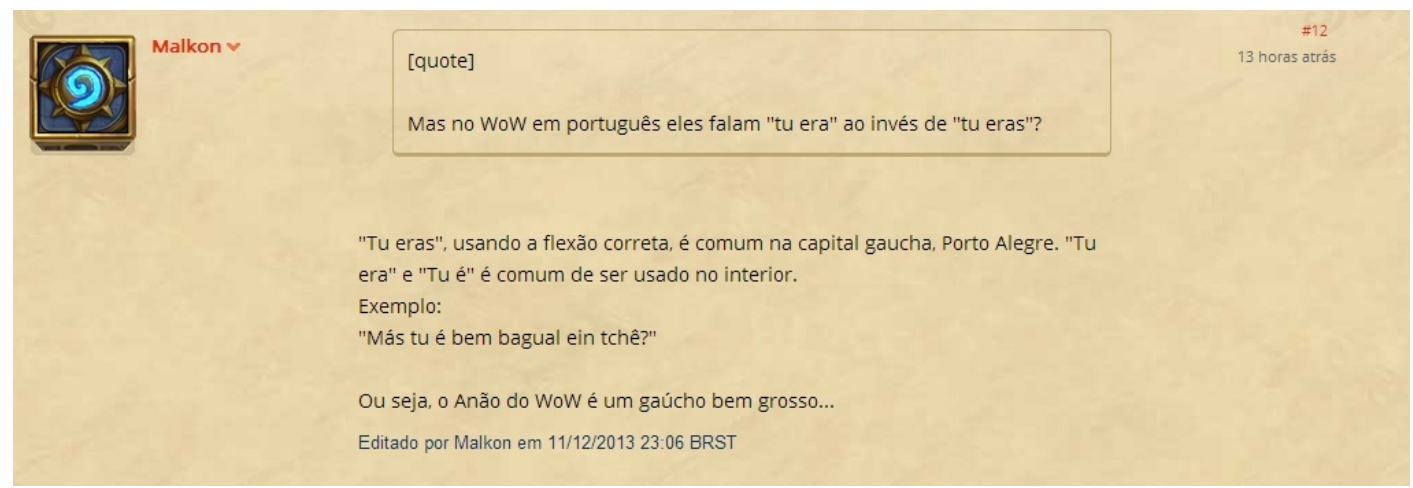

Esses comentários, retirados do fórum do Hearthstone ${ }^{54}$, respondem a um usuário que apontava os usos Tu é/Tu pode/Tu desbloqueou/Tu tem na fala de um anão que introduz o jogo como "erros grosseiros” e "defeitos”. Porém, esses jogadores não só reconhecem a variedade como legítima, como também identificam a região a que pertence. Há usuários que simplesmente não aceitam o fato de existirem dialetos e respectivos sotaques no jogo, apresentando-se decepcionados.

\footnotetext{
${ }^{53}$ Por exemplo, Bagno (2011, p. 539) elenca quatro paradigmas verbais em uso no Brasil, sendo este o terceiro grau (C) no continuum que vai da variedades de menor prestígio social (A) para a de maior prestígio social (D).

${ }^{54}$ Hearthstone é um jogo digital de cartas que usa personagens, habilidades e criaturas do universo Warcraft, semelhante em aparência e mecânica de jogo ao tradicional Magic: The Gathering (Wizards of the Coast, 1993).
} 
Amostra 16 - Battle.net/hearthstone

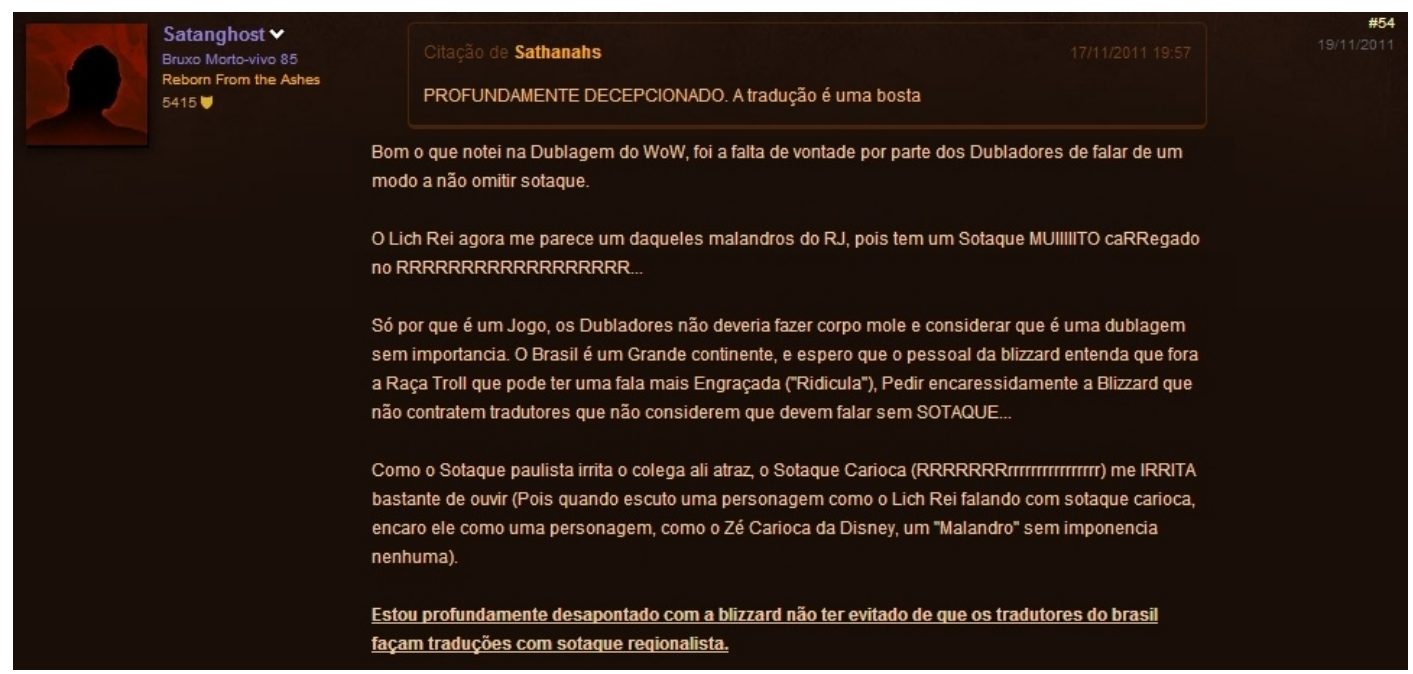

Esta amostra é apenas um exemplo de revolta contra a simples existência de dialetos no jogo. A frustração do jogador da Amostra 16 é reflexo do seu desconhecimento em relação ao funcionamento da língua: seu apelo por uma fala "sem sotaque” expressa nada mais do que uma ilusão de que existe um português fora da comunidade linguística — o que não tem base real (cf. ALKMIM, 2007). Na verdade, ele parece querer o uso de uma única variedade (talvez a usada na mídia) para representar todas as raças, o que vai claramente contra os objetivos da localização. Resta-lhe, obviamente, o direito subjetivo de não apreciar tais objetivos.

\section{Considerações Finais}

Ainda que este texto tenha dado apenas os primeiros passos para uma pesquisa a fundo sobre o assunto, acreditamos que analisando o problema da tradução dos dialetos nos jogos pudemos compreender melhor a natureza da localização, enxergando sua nítida valorização do "texto-alvo", em sentido amplo; sua forma de usar elementos do real para construir a experiência de jogo; e seu potencial para construir identidades.

Pudemos constatar também que, assim como em outros produtos culturais, a variação linguística não pode ser negligenciada, sob pena de se prejudicar a experiência do jogador do game localizado. O teor dos comentários acima, críticos ou elogiosos, revela a importância de lidar com as variedades linguísticas na localização de um jogo: a presença dos dialetos influenciou a forma como os personagens e as raças foram construídos pela desenvolvedora do jogo (que tem suas próprias concepções sobre seu produto) e depois reconstruídas pelos jogadores em sua recepção do jogo localizado - mediada por sua visão de mundo, expectativas, sua própria identidade regional e social, incluindo possíveis estereótipos, entre outros.

Além disso, o fato de os jogadores terem identificado os dialetos e os associado a estereótipos de seu imaginário, expressando reações positivas e negativas, é prova de que a cultura local foi reconhecida pelo público-alvo da localização do WoW e que, portanto, a ponte com o real (o vínculo familiar de que falamos) foi es- 
tabelecida, tal como ocorre com o jogo em inglês. Ou seja, não houve estranhamento, mas reconhecimento. ${ }^{55}$

Vimos também que a localização dos dialetos provocou discussões sobre questões sociais, como o preconceito social e racial; questões linguísticas, como o português padrão (o que é erro e o que não é); e questões da experiência de jogo. Nesse aspecto, vimos que alguns jogadores mencionaram que a existência de "sotaque” local dificulta a imersão; outros alegaram que isso contribui para tal imersão.

As discussões no fórum também poderiam gerar outros caminhos de pesquisa, como, por exemplo a investigação de como concepções dos usuários sobre língua, tradução, localização afetam a experiência de jogo; ou a análise dos discursos que defendem o jogo em português pelo viés do nacionalismo e do amor à língua nativa; ou ainda se a importância e a tradição do inglês na cultura de games/ficção exerce influência sobre a experiência de jogo, o que poderia explicar o fato que mencionamos antes de alguns jogadores brasileiros defenderem que nomes próprios, mesmo traduzíveis, sejam mantidos em inglês, advogando em favor de uma localização parcial ${ }^{56}$.

Por fim, baseado no que apresentamos, esperamos ter reforçado a incipiente hipótese de que a localização de games desafia concepções mais rígidas de tradução, suscitando a necessidade de lançar um novo olhar sobre o campo e sua terminologia.

Heber de Oliveira Costa e Silva heber1979@gmail.com Doutorando em Letras, Universidade Federal de Pernambuco

\footnotetext{
${ }^{55}$ Em sua conhecida formulação, Humboldt (apud LEFEVERE, 2004, p. 138) diz que, quando não se sente a estranheza, mas sim o estrangeiro, a tradução cumpriu seu papel supremo.

${ }^{56}$ Se para alguns, isso melhoraria a experiência de jogo; para outros, talvez prejudicasse, pois nomes como Hellscream, por exemplo, são mera justaposição de palavras compreensíveis ao jogador original. Em alguns casos, esses nomes contribuem para caracterizar o personagem e estão associados à história do game.
} 


\title{
APÊNDICE -
}

\section{Comentários em fóruns e sites não oficiais}

\author{
Comentário 1 - Codex
}

\section{Xcrazy}

October 10, 2011 at 1:47 pm (UTC -2)

Não vou tirar o mérito de algo que vai trazer minha vontade de jogar denovo mas, fala sério, tem TRÊS dubladores.

Porra, pega o dublador do Gimli pra fazer os anões kct!! Qto deve custar um dublador, deve ser 1/10 do valor de um dev. A voz tosca dos anões está parecendo com a voz de um metaleiro que não consegue fazer voz de black metal.

Gnomos e Goblins são caso a parte.

Trolls, tem uns que parecem a tartaruga do Nemo. Só falta eles chamarem agente pra surfar na corrente norte atlantica.

Bom, não dou nota 10, como vc. Acho que a vontade de ter um produto em portugues superou seu senso crítico, mas nos padrões Lula de qualidade, onde 5 é uma nota boa, WoW BR é bem classificado, no meu ponto de vista, com uma nota 7 .

Obs... os maloqueiros verdes são um show a parte.

\section{Comentário 2 - Codex}

\section{shadowbloody}

October 11,2011 at 2:07 am (UTC -2)

Algumas ficaram bacanas outras mais ou menos, Os Trolls perdeu a essência de ter um tipo de sotaque Indigena macumbeiro Voodo pra Carioca Funkeiro malandro como vc mesmo comentou, os Goblins estão tbm na mesma linha sei lá, uma coisa que não gostei muito é que toda cidade tem o nome traduzido de forma literal exemplo Lua Prata, soa bem estranho, custava colocar Lua de Prata ia ficar bem melhor.

Mas de modo Geral está bem bacana. 


\section{Comentário 3 - WoWGirl}

Arcturos@tolbarad - 7 meses atrás

O Marés da Guerra é excelente, e aguardo ancioso pelo próximo !!! Ótima noticia.

A unica coisa que realmente acho uma pena , foi o "dialeto" usado para os Trolls. Se voce perceber no jogo em Ingles, SIM eles falam errado, mais remetendo aos africanos e a sua pronuncia tribal. Já no portugues tentaram fazer um negócio que não colou muito bem na minha opiniao... um tom meio de Carioca Malandrão Maconheiro das quebrada....

Sim é divertido, suas piadinhas e tal... e o "Voodoo é pra Jacu"... é impagavel, foi a melhor coisa que aconteceu no WOW em português... mas sei lá não ficou digamos, consistente com o lore da raça que é uma coisa bem nativa. me incomoda bastante.

Daqui a pouco vao fazer um emote dos Trolls cantando Lelek Lek Lek Lek .... shhhhhhhhhhh melhor nao dar idéia.... já to ate imaginando nas BGs...

$\wedge \mid \vee \cdot$ Responder * Compartilhar ,

Facanegra@Tolbarad †Arcturos@tolbarad.7 meses atrás

Olha eu ja gostei bastante do sotaque deles em português, afinal foi baseado em um sotaque mais hippie, rastafari entende perceba que eles usam girias e falam num jeitão beeemmm de boa e em inglês o sotaque deles lembra muito um jeitão mas jamaicano/rastafari tambem foi disso que eles tiraram a ideia entendeu

\section{Comentário 4 - MMORPGS}

A qualidade das vozes ficaram boas, sim. Só não achei legal os goblins e os trolls serem tão malandros e todo esse sotaque carregado sem nenhum motivo.

\section{Nagwarr disse:}

um leve sotaque carioques que é bem melhor do que o sofrivel sotaque paulista

Tenebrus

um leve sotaque carioques que e bem melhor do que o sofrivel sotaque paulista

Por isso deveriam ser dubladores paulistanos. Toda vez que ouço um "x" no lugar de um "s", ou "rr" no lugar de "r", me dá um desânimo terrível.

Tenebrus, 11 de Outubro de 2011 


\section{Referências bibliográficas}

AlKmim, T. Sociolinguística: parte 1. In: Mussalim, F.; Bentes, A.C. Introdução à Linguística: domínios e fronteiras, v. 1. São Paulo: Cortez, 2007, p. 2147.

Bagno, M. Gramática pedagógica do português brasileiro. São Paulo: Parábola, 2011.

Berman, A. La traducción como experiencia de lo/del extranjero. La traduction comme épreuve de l'étranger. Trad. Claudia Ángel, Martha Pulido. Colección Hermes, Traductologia: Cuadernos Pedagógicos, n. 2. Universidad de Antioquia: Medellín, 2005.

Bernal-Merino, M. On the translation of video games. The Journal of Specialized Translation. Issue 6. July. 2006. pp. 22-36. ISSN 1740-357X. Disponível em: <http://www.jostrans.org/issue06/art_bernal.pdf $>$. Acesso em: 19 set. 2014.

. What is in a 'game'?. The International Journal of Localization, v. 6, issue 1, pp. 29-38, 2008. Disponível em:

<http://www.localisation.ie/resources/lfresearch/Vol6_1Bernal.pdf>. Acesso em: $14 \mathrm{dez} 2013$.

Camacho, R. Sociolinguística: parte 2. In: Mussalim, F.; Bentes, A.C. Introdução à Linguística: domínios e fronteiras, v. 1. São Paulo: Cortez, 2007, p. 49-75.

Chandler, H.; Deming, S. The game localization handbook. 2. ed. Sudbury/Ontario/London: Jones \& Bartlett Learning, 2012.

Costa E Silva, H. de O. Tradução e dialogismo: um estudo sobre o papel do tradutor na construção do sentido. Recife: Edufpe, 2011.

Crystal, D. The Penguin dictionary of language. 2. ed. Chippenham, UK: Penguin, 1999.

Di MARCo, F. Cultural Localization: Orientation and Disorientation in Japanese Video Games. In: Revista Tradumàtica, n. 5, nov. 2007. Disponível em: $<$ http://www.fti.uab.cat/tradumatica/revista>. Acesso em: 14 dez 2013.

Esselink, B. A practical guide to localization. Philadelphia/Amsterdam: John Benjamins, 2000.

FEDERICI, F. Introduction: Dialects, idiolects, sociolects: Translation problems or creative stimuli?. In: New Trends in Translation Studies, v. 6, p. 1-5. Bruxelles: Peter Lang, 2011.

FOLKART, B. Les conflits des énonciations: traduction et discours rapporté. Candiac, Québec: Les Éditions Balzac, 1991.

FORBES. 'World of Warcraft' still a $\$ 1 B$ powerhouse even as subscription MMOs decline. 19/07/2014. Disponível em:

$<$ http://www.forbes.com/sites/insertcoin/2014/07/19/world-of-warcraftstill-a-1b-powerhouse-even-as-subscription-mmos-decline/>. Acesso em: 20 set. 2014.

G1 - Portal de notícias da Globo. 'World of Warcraft' chega oficialmente ao Brasil no dia 6 de dezembro. 08/11/2011. Disponível em:

<http://g1.globo.com/tecnologia/noticia/2011/11/world-warcraft-chegaoficialmente-ao-brasil-no-dia-6-de-dezembro.html>. Acesso em 19 set 2014. 
HERmAns, T. Translation in systems: descriptive and system-oriented approaches explained. Manchester: John Benjamins; Shanghai: Shanghai Foreign Language Education Press, 2004 [1999].

Dicionário eletrônico HouAISs da língua portuguesa. Instituto Antônio Houaiss/Editora Objetiva, 2001. CD-ROM.

LefEVERE, A. (ed.) Translation/History/Culture: a sourcebook. London: Routledge; Shanghai: Shanghai Foreign Language Education Press, 2004 [1992].

. Tradução, reescrita e manipulação da fama literária. Trad. C. M. Seligmann. Bauru: Edusc, 2007.

MANGIRON, C. Bringing fantasy in reality: localizing Final Fantasy. Global Insider (LISA), issue 1.3, 2004. Disponível em:

$<$ https://www.academia.edu/1226443/Bringing_Fantasy_to_Reality>.

Acesso em: $20 \mathrm{dez} 2013$.

O’HAGAN, M. Video games as a new domain for translation research: from translating text to translating experience. In: Revista Tradumàtica, n. 5, nov. 2007. Disponível em: <http://www.fti.uab.cat/tradumatica/revista>. Acesso em: 14 dez. 2013.

. Putting pleasure first: localizing Japanese video games. In: TTR: traduction, terminologie, rédaction, v. 22, n. 1, 2009, p. 147-165.

O'HAGAN, M.; MANGIRON, C. Game localization: when "arigato” gets lost in translation. In: Proceedings of New Zealand Game Developers Conference, 2004. Disponível em:

<https://www.academia.edu/3696840/Game_Localization_When_Arigato_ gets_lost_in_translation>. Acesso em: 20 dez. 2013.

. Game localization: unleashing imagination with 'restricted' translation. In: The Journal of Specialized Translation, issue 6, July 2006, pp. 10-21. Disponível em: <http://www.jostrans.org/issue06/issue06_toc.php>. Acesso em: $11 \mathrm{dez} 2013$.

. Game localization. Amsterdam/Philadelphia: John Benjamins, 2013.

PyM, A. Exploring Translation Studies. London/New York: Routledge, 2010.

Shuttleworth, M; Cowie, M. Dictionary of translation studies. Manchester: St. Jerome; Shanghai: Shanghai Foreign Language Education Press, 2003.

SNELl-HoRnBY, M. Translation studies: an integrated approach. Amsterdam/Philadelphia: John Benjamins; Shanghai: Shanghai Foreign Language Education Press, 2001 [1995].

SUPERDATA Research - digital goods measurement. Brazil digital games market report 2014. Disponível em: <http://www.superdataresearch.com/marketdata/brazils-online-gaming-market/> . Acesso em: 21 set. 2014.

TAIVALKOSKI-SHILOV, K. La tierce main: discours rapporté, traduction et Fielding en France au XVIIIe siècle. Thèse pour le doctorat. Helsinki: Université de Helsinki, 2003.

. When two become one: reported discourse viewed through a translatological perspective. In: AZADIBOUGAR, O. (ed.). Translation Effects. Selected Papers of the 2009 Research Seminar in Translation Studies CETRA. 2010. Disponível em: <http://www.kuleuven.be/cetra/papers/papers.html>. Acesso em: 10 dez 2013.

TRASK, R. L. Dicionário de Linguagem e Lingüística. Trad. Rodolfo Ilari. São Paulo: Contexto, 2008.

Venuti, L. The translator’s invisibility. New York: Routledge, 1997. 
Escândalos da tradução. Trad. de L. Pelegrin, L. Villela, M. Esqueda, V. Biondo. Bauru: Edusc, 2002.

VIDAL, C.; EliAs, I. When Brazil Enters in the Koprulu Sector: the Starcraft II Localized into Brazilian Portuguese. In: Proceedings of SBGames 2012. XI SBGames, Brasília, 2012. Disponível em: http://sbgames.org/sbgames2012/proceedings/papers/cultura/C_F14.pdf. Acesso em: 15 nov 2013. 